\title{
BACTERIAL PERMEABILITY OF TIN-SEALED SAUSAGE CASING
}

\author{
Masashi Nakaide, Shizuo Nakajima, Taeko Kasegai and Katsumi Ito \\ (Received November 9, 1964)
}

\begin{abstract}
Synopsis
Considerable loosening at the tin-seal of the casing of commercial fish sausage was observed after heat pasteurization by measurement of electrical resistance of the opening at the seal before and after heating. The seal of the specially prepared stuffingless casing seemed to enlarge to some degree while it was hot, and thereafter it narrowed again after cooling with water. It would be assumed that a tiny piece of meat clogging in the seal of stuffed casing readily occurs to fall off.

A devised culture assembly demonstrated that majority of the tin-sealed casings tested had free bacterial permeability at the seal, and even the mechanically tightest seal gave no reproducible resistance against bacterial passage. Industrial cleanliness of cooling water and dry storage were also discussed from standpoint of food sanitation.
\end{abstract}

\section{Introduction}

Although many studies ${ }^{1-5)}$ on the spoilage of commercial sausage have been found since they began to come into the market, very few works ${ }^{21,6)}$ have been reported on bacterial infection through the opening of the casing sealed with tin, wire or thread. It is well known that a single pinhole on the film of the casing must cause rapid and severe spoilage, and it seems more important to learn that it is concluded, from bacteriological point of view, to be extraordinarily difficult to cool a cooked tin-sealed sausage in tap water without danger of unfavorable bacterial invasion.

This work was therefore undertaken to ascertain whether bacteria may pass through the extremely narrow opening at the tin-seal of cooked sausages, and whether heat treatment for pasteurization may have any influence on the size of the opening of sausage casings made of several kinds of plastic films.

\section{Experimental}

Casing. Some commercial fish sausages sealed with tin (or wire) were used for testing bacterial permeability of plastic casing. Most of them were stuffed in either colorless or dyed tubes of 0.04 milimeter thick Kurehalon (or Ryphan) and sealed with aluminum wire or with aluminum belt. Other 'stuffingless' casings with seal were directly obtained from some leading manufactories. These unstuffed samples had been automatically sealed using empty tube, and some of these were classified into three groups according to durability against air pressure; first group consists of the casing that gives many air babbles through the seal at pressure less than $0.5 \mathrm{~kg}$ per $\mathrm{cm}^{2}$, second group starts babbling at $0.5 \mathrm{~kg}$ per $\mathrm{cm}^{2}$ and third at $1.0 \mathrm{~kg}$ per $\mathrm{cm}^{2}$.

Organism. Escherichia coli, IFO 3806, was used throughout this work. A stock 
culture grown on bouillon agar slant was subcultured for 24 hours at $37^{\circ} \mathrm{C}$ in $\mathrm{LB}$ medium containing $1 \%$ peptone, $0.3 \%$ bouillon, $0.5 \%$ lactose and $0.0024 \%$ bromthymol blue. An aliquot of the cultured broth was pipetted out for the final inoculation in this experiment.

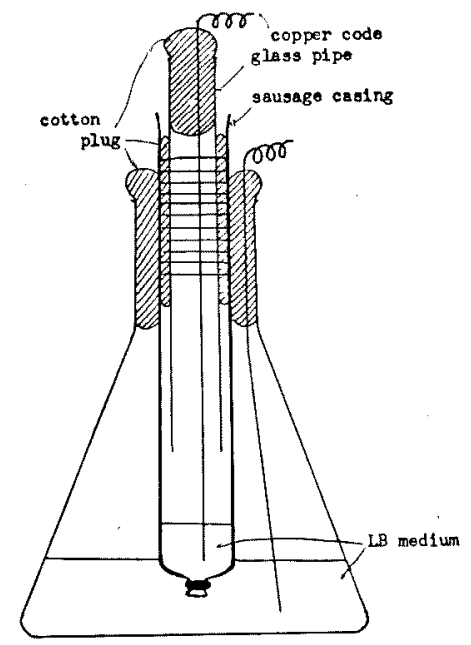

Fig. 1. Culture assembly used for detecting bacterial permeability of sausage casing.

Culture assembly. The tin-sealed casings of plastic film to be tested were gathered by peeling off commercial sausages or by scraping out their contents, followed by washing with soap. After they were rinsed with distilled water each empty casing was fixed firmly with cotton thread around a glass pipe ( $13 \mathrm{~mm}$ diameter, $120 \mathrm{~mm}$ ) which was surrounded with cotton of a few milimeter thick, then the fixed bag was vertically suspended down in a $300-\mathrm{ml}$ Erlenmeyer flask containing $200-\mathrm{ml}$ of the growth medium for $E$. coli, and fixed again at the neck of the flask with a cotton plug through which a copper code was inset and the height of the lead was adjusted to sink the end deep enough in the growth medium. From the top of the glass pipe two to five mililiters of the same growth medium poured onto the bottom of the tin-sealed casing and the pipe was stopped with another cotton plug through which the other copper code was inserted and the lower end of the lead was adjusted to reach the surface of the inner growth medium in the bag. The whole assembly is illustrated in Fig. 1. In the case of small sample which is short in length not enough to be fixed around the glass pipe as above described, epoxy resin adhesive No. 1500 (Cemedine Co., Ltd) was used for attaching it to the pipe instead of inner cotton plug; the short casing adhering around the glass pipe was firmly fixed with cotton thread and solidified in a dry oven at $80^{\circ} \mathrm{C}$ for three hours. The adhesion of the bag on the surface of the glass was proved satisfactory with following examination.

Examination for pinholing and resin adhesiveness. For detecting pinholing and loose adhesion between the glass pipe and plastic film the casing was filled with water, into which one terminal of a modified Nichirei pinhole tester, P-5, was inserted, and the surface of the film was carefully smoothed over with the other terminal, which was nipping a tiny piece of wet rag, to find any spot to admit direct current more than $1.0 \mu \mathrm{A}$. To further confirming safety the eligible sample chosen by the above examination was then immersed into a beaker in which an adequate amount of water formed an upper layer on a bed of chloroform until the sealing wire at the end of the casing reached the surface of the lower layer, followed by checking direct 
current between the water in the casing and the water in the beaker (Fig. 2).

Sterilization. The whole assembly which had passed the electrical examination for pinholing was sterilized at $120^{\circ} \mathrm{C}$ for 15 minutes, or by Koch pasteurization at $90-95^{\circ} \mathrm{C}$. Before and after heating direct current which flows from one end of the copper lead to an end of the other code was measured with the tester, and the figure was converted to resistance by calculation.

Inoculation and detection of permeability.

After sterilization the inner medium, unless otherwise noted, was inoculated with the 24-hour cultured broth of E. coli, and incubated at $37^{\circ} \mathrm{C}$ in a week. The $\mathrm{LB}$ medium in the assembly is deep greenish blue before inoculation and it turns yellow and turbid when $E$. coli inoculated multiplies normally overnight, due to production of lactic acid. Cell permeability of the seal of the casing was thereby readily detected to observe whether the sterile (non-inoculated) medium changed yellow and turbid during incubation after the opposite medium was inoculated. Normally one $\mathrm{ml}$ of the medium showing growth of $E$. coli contains

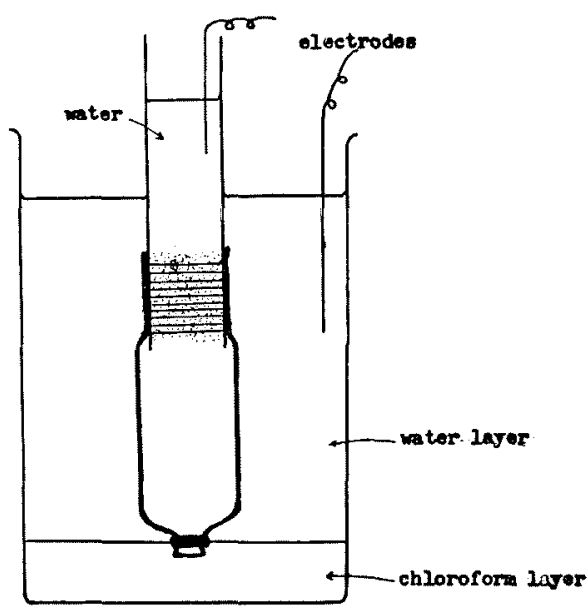

Fig. 2. Examination for pinholing and resin adhesiveness. more than $10^{9}$ cells.

\section{Results and Discussion}

All assemblies were sterile before inoculation and as to each of the casings in the flask electrical resistance at its opening was estimated before heating, immediately after heated and after cooled with water (Tables I and II). Commercial fish sausages are demonstrated to have the seal which gives considerably low resistance; some of them indicated $50 \mathrm{M} \Omega$ or more before heating, which changed to show far lower figures after first cooking. The breakdown of resistance at the seal of these casings prepared from commercial (stuffed) sausage remained almost unchanged after they were cooled down to room temperature (Table I). From these results it would be suggested that the opening of the seal must hold small piece of pressed stuffing between therein overlapping walls of film, and the meat may be apt to fall off by cooking or by its repetition.

Similar results were obtained from the assemblies in which the stuffingless casings were inset (Table II-1); the first group $(\mathrm{K}-1 \sim 10)$ that permits air to pass through the seal at lowest pressure indicated relatively small value of electrical resistance: It is of interest to observe that, though resistance of the stuffingless casing lowered 
by heating, it quickly increased up to its original level by cooling with water, and this tendency was nominant in the second $(L-1 \sim 10)$ and the third $(M-1 \sim 10)$ groups. Consequently it would be assumable that the hole at the seal of the unstuffed casing slightly widens by cooking probably due to heat expansion of the sealing ring, and that it must be able to shrink again down nearly to original size or less because of the change of film thickness. Conductivity of the LB medium itself was observed to slightly increase while it was hot, but correction for increase of temperature was overlooked in this experiment.

On the contrary, the size of the opening at the seal of stuffed casings appears

Table I-1. Electrical resistance at the seal of the casing of commercial fish sausage and bacterial permeability

\begin{tabular}{|c|c|c|c|c|c|c|c|c|c|c|}
\hline \multirow{2}{*}{$\begin{array}{l}\text { No. of } \\
\text { assembly }\end{array}$} & \multicolumn{3}{|c|}{$\begin{array}{l}\text { Electrical resistance } \\
\text { in } L B \text { medium }(\mathrm{M} \Omega)\end{array}$} & \multicolumn{7}{|c|}{$\begin{array}{l}\text { Infection by } E \text {. coli } \\
\text { (days after inoculation) }\end{array}$} \\
\hline & I & II & III & 1 & 2 & 3 & 4 & 5 & 6 & 7 \\
\hline A-1 & 0.95 & 0.09 & 0.10 & + & & & & & & \\
\hline 2 & 0.38 & 0.27 & 0.30 & - & + & & & & & \\
\hline 3 & 0.38 & 0.53 & 0.65 & - & + & & & & & \\
\hline 4 & 3.0 & 0.13 & 0.54 & - & + & & & & & \\
\hline 5 & 0.29 & 0.13 & 0.46 & + & & & & & & \\
\hline 6 & 1.2 & 0.46 & 0.70 & + & & & & & & \\
\hline 7 & 1.2 & 0.80 & 0.84 & - & + & & & & & \\
\hline 8 & 3.0 & 0.50 & 0.30 & - & + & & & & & \\
\hline 9 & 1.9 & 1.5 & 1.8 & - & + & & & & & \\
\hline 10 & 4.4 & 10 & 28 & - & + & & & & & \\
\hline B-1 & 0.75 & 0.11 & 0.15 & - & + & & & & & \\
\hline 2 & 28 & 0.62 & 0.70 & + & & & & & & \\
\hline 3 & 0.84 & 1.9 & 0.80 & - & - & - & - & - & - & - \\
\hline 4 & 1.9 & $<0.06$ & $<0.06$ & - & + & & & & & \\
\hline 5 & 0.68 & 0.06 & $<0.06$ & - & - & - & - & - & - & - \\
\hline 6 & 50 & 0.29 & 0.38 & - & - & + & & & & \\
\hline 7 & 2.0 & $<0.06$ & $<0.06$ & + & & & & & & \\
\hline 8 & 0.06 & $<0.06$ & 0.42 & + & & & & & & \\
\hline 9 & 2.6 & $<0.06$ & $<0.06$ & + & & & & & & \\
\hline 10 & 4.4 & 0.46 & 0.83 & - & + & & & & & \\
\hline C-1 & 28 & $<0.06$ & $<0.06$ & - & + & & & & & \\
\hline 2 & $>50$ & 2.6 & 2.6 & - & - & - & - & - & - & - \\
\hline 3 & 4.4 & 1.9 & 28 & - & + & & & & & \\
\hline
\end{tabular}

I: Before heating

II: Immediately after heating

III: After cooling with water

Sterilization was carried out at $120^{\circ} \mathrm{C}$ for 15 minutes.

Calculation for the figures more than $50 \mathrm{M} \Omega$ or less than $0.06 \mathrm{M} \Omega$ was abridged.

Group B: Ryphan casing 
Table I-2. Electrical resistance at the seal of the casing of commercial fish sausage and bacterial permeability

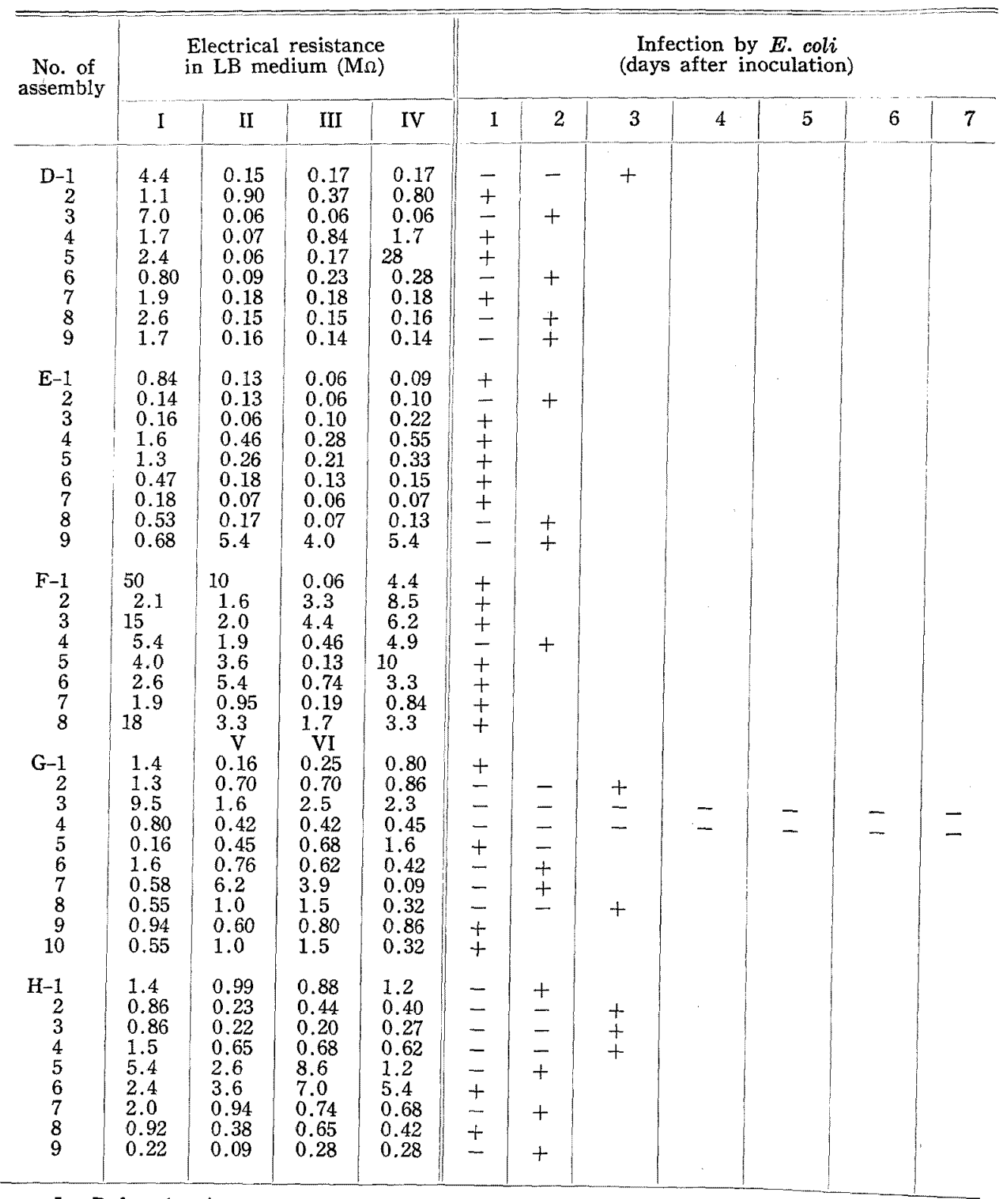

I: Before heating

II: After first heating and cooling

III: Immediately after third heating

IV: After third cooling

V: Immediately after first beating

VI: After first heating and cooling (II)

Sterilization was carried out three times at $90-95^{\circ} \mathrm{C}$ for 30 minutes at 24 -hour invervals. 
to be difficult, when they are cooled, to shrink back to the original since a tiny piece of the stuffed meat at the seal, as mentioned before, is apt to fall off during sterilization. In most cases, the seals of commercial sausages after cooking are left looser than that before heating, and this assumption is in good accordance with experimental results. A few samples of commerce, however, revealed good reversible increase of electrical resistance even by repetition of heating, and it probably means that the tiny piece of meat did not occur thereby to fall off.

Since the size of the opening can be practically too narrow to admit fungal mycelia or microscopic dust, and even smaller particles such as yeast or bacteria have been proved to be unable to pass into the casing when the seal is dried as many previous reports says, it would be favorable in industrial manufacture of fish sausage to manage the seal after cooled in water as dehydrated as possible for protection and similar prudence had better be paid for further storage; the more moisture must cause the more rapid putrefaction.

Bacterial passage through the seal was obviously illustrated by detecting the infection of sterile medium by $E$. coli; the results in Tables I and II show that more than 90 per cent of sterile media in the assemblies changed yellow and turbid during 3-day incubation after the opposite media were inoculated. No significant difference in easiness of bacterial passage was observed between commercial casings and the stuffingless casings of the first and second groups. As to a half of the assemblies, which had the casings of the tightest seal therein, the media in the flasks of the other half were inoculated for the comparison of ability of bacterial dispersion towards outside with that of invasion towards inside. The data shown in Table II-2 prove that both invasion and dispersion of microorganisms through the seal have no difference in easiness in the present condition.

Only 5 samples out of 68 commercial sausages casings could avoid bacterial infection by severe immersion into the broth where the number of cells of $E$. coli would reach more than $10^{\circ}$. These results mean that something too hard to pass through must be held in the seal since some of these samples revealed considerably low value of electrical resistance at the seal, and presumably, a few of this kind of the casing seem statistical to be produced.

The results in these experiments also gave evidence to decide that even the tightest seals were uncapable of interrupt bacterial passage, and from these phenomena an alarm should be given to the manufacturers of sausage to correct misunderstanding that the current seal of the tin-sealed casing has good durability against bacterial invasion, and moreover, tap water used for cooling in the factory should be kept as clean as possible to avoid initial and serious step of infection.

In conclusion, though the casings giving high electrical resistance at the seal show comparatively better in resistance to bacterial permeation, safety of the seal of sausage is incomparably inferior to that of canned food. 
Table II-1 Electrical resistance at the seal of the stuffingless casing of fish sausage and bacterial permeability

\begin{tabular}{|c|c|c|c|c|c|c|c|c|c|c|c|c|c|c|}
\hline \multirow{2}{*}{$\begin{array}{l}\text { No. of } \\
\text { assembly }\end{array}$} & \multicolumn{7}{|c|}{ Resistance in LB medium $(\mathrm{M} \Omega)$} & \multicolumn{7}{|c|}{$\begin{array}{c}\text { Infection by } E \text {. coli } \\
\text { (days after inoculation) }\end{array}$} \\
\hline & 1 & II & III & IV & $\mathrm{V}$ & VI & VII & 1 & 2 & 3 & 4 & 5 & 6 & 7 \\
\hline $\mathrm{K}-1$ & 0.72 & 0.44 & 0.76 & 0.44 & 0.84 & 0.49 & 0.74 & + & & & & & & \\
\hline 2 & 0.32 & 0.47 & 0.70 & 0.58 & 0.76 & 0.62 & 0.70 & + & & & & & & \\
\hline 3 & 0.38 & 0.24 & 0.47 & 0.24 & 0.47 & 0.23 & 0.44 & - & + & & & & & \\
\hline 4 & 0.54 & 0.49 & 0.76 & 0.58 & 0.84 & 0.60 & 0.80 & + & & & & & & \\
\hline 5 & 0.70 & 0.50 & 1.0 & 0.60 & 1.1 & 0.55 & 1.1 & + & & & & & & \\
\hline 6 & 0.65 & 0.58 & 1.5 & & & & & + & & & & & & \\
\hline 7 & 0.34 & 0.47 & 1.8 & & & & & + & & & & & & \\
\hline 8 & 0.60 & 1.1 & 0.65 & & & & & + & & & & & & \\
\hline 9 & 1.7 & 0.47 & 1.7 & & & & & + & & & & & & \\
\hline 10 & 0.65 & 0.70 & 1.8 & & & & & + & & & & & & \\
\hline L-1 & 10 & 4.0 & 7.8 & 4.0 & 8.4 & 13 & 10 & + & & & & & & \\
\hline 2 & 28 & 13 & 28 & 13 & 50 & 28 & 32 & + & & & & & & \\
\hline 3 & 50 & 2.8 & 28 & 13 & 50 & 8.4 & 50 & - & + & & & & & \\
\hline 4 & 50 & 13 & 28 & 20 & 32 & 28 & $>50$ & + & & & & & & \\
\hline 5 & 3.5 & 4.0 & 4.0 & 6.2 & 4.4 & 28 & 5.4 & + & & & & & & \\
\hline 6 & 50 & 6.2 & 20 & & & & & + & & & & & & \\
\hline 7 & 50 & 4.4 & 32 & & & & & + & & & & & & \\
\hline 8 & 10 & 3.0 & 10 & & & & & + & & & & & & \\
\hline 9 & 18 & 6.2 & $>50$ & & & & & + & & & & & & \\
\hline 10 & 5.4 & 13 & 32 & & & & & + & & & & & & \\
\hline M-1 & 32 & 15 & 28 & 50 & 32 & 50 & 50 & - & + & & & & & \\
\hline 2 & $>50$ & 28 & $>50$ & 32 & $>50$ & 28 & $>50$ & + & & & & & & \\
\hline 3 & $>50$ & 32 & $>50$ & 20 & $>50$ & 20 & $>50$ & - & + & & & & & \\
\hline 4 & $>50$ & 28 & $>50$ & 32 & $>50$ & 20 & $>50$ & - & - & - & - & - & - & - \\
\hline 5 & $>50$ & 32 & $>50$ & 50 & $>50$ & 13 & $>50$ & - & - & + & & & & \\
\hline 6 & $>50$ & 5.4 & $>50$ & & & & & - & - & - & + & & & \\
\hline 7 & $>50$ & 2.3 & $>50$ & & & & & + & & & & & & \\
\hline 8 & $>50$ & 10 & $>50$ & & & & & - & + & & & & & \\
\hline 9 & $>50$ & 15 & $>50$ & & & & & - & + & & & & & \\
\hline 10 & $>50$ & 28 & $>50$ & & & & & + & & & & & & \\
\hline
\end{tabular}

Koch pasteurization was carried out for the samples of No. 1-5, and the samples of No. 6-10 were sterilized at $120^{\circ} \mathrm{C}$ for 30 minutes.
I: Before heating
II: Immediately after first heating
III: After first cooling
IV: Immediately after second heating
V: After second cooling
VI: Immediately after third heating
VII: After third cooling 
Table II-2. Electrical resistance at the tightest seal of the stuffingless casing of fish sausage and bacterial permeability

\begin{tabular}{|c|c|c|c|c|c|c|c|c|c|c|c|c|}
\hline \multirow{2}{*}{$\begin{array}{l}\text { No. of } \\
\text { assembly }\end{array}$} & \multicolumn{3}{|c|}{$\begin{array}{l}\text { Resistance in } L B \\
\text { medium }(M \Omega)\end{array}$} & \multicolumn{2}{|c|}{ Inoculation } & \multicolumn{7}{|c|}{$\begin{array}{l}\text { Infection by } E . \text { coli } \\
\text { (days after inoculation) }\end{array}$} \\
\hline & I & II & III & $\begin{array}{c}\text { inner } \\
\text { medium }\end{array}$ & $\begin{array}{c}\text { outer } \\
\text { medium }\end{array}$ & 1 & 2 & 3 & 4 & 5 & 6 & 7 \\
\hline $\mathrm{N}-1$ & $>50$ & 8.4 & $>50$ & + & & + & & & & & & \\
\hline 2 & $>50$ & 10 & $>50$ & + & & + & & & & & & \\
\hline 3 & $>50$ & 5.4 & $>50$ & + & & + & & & & & & \\
\hline 4 & $>50$ & 8.4 & $>50$ & + & & - & - & - & - & - & - & - \\
\hline 5 & 50 & 1.2 & 2.1 & + & & - & - & - & - & - & - & - \\
\hline 6 & $>50$ & 8.4 & $>50$ & & + & + & & & & & & \\
\hline 7 & $>50$ & 10 & $>50$ & & + & - & + & & & & & \\
\hline 8 & $>50$ & 13 & $>50$ & & + & + & & & & & & \\
\hline 9 & $>50$ & 13 & $>50$ & & + & - & + & & & & & \\
\hline 10 & 32 & 10 & $>50$ & & + & - & + & & & & & \\
\hline 11 & - & - & $>50$ & + & & - & + & & & & & \\
\hline 12 & - & - & $>50$ & + & & + & & & & & & \\
\hline 13 & - & - & $>50$ & + & & - & - & - & - & - & - & - \\
\hline 14 & - & - & $>50$ & + & & - & + & & & & & \\
\hline 15 & - & - & $>50$ & + & & - & - & + & & & & \\
\hline 16 & - & - & $>50$ & & + & - & - & - & - & - & - & - \\
\hline 17 & - & - & $>50$ & & + & + & & & & & & \\
\hline 18 & - & - & $>50$ & & + & - & + & & & & & \\
\hline 19 & - & - & $>50$ & & + & - & - & - & - & - & - & - \\
\hline 20 & - & - & $>50$ & & + & - & + & & & & & \\
\hline
\end{tabular}

Sterilization was carried out at $120^{\circ} \mathrm{C}$ for 15 minutes.
I: Before heating
II: Immediately after heating
III: After cooling

\section{Summary}

1) Considerable loosening at the tin-seal of the casing of commercial fish sausage was observed after pasteurization by measurement of electrical resistance of the opening at the seal before and after heating.

2) The seal of the specially prepared stuffingless casing seemed to enlarge to some degree while it was hot, but the opening narrowed again after cooling.

3) Majority of the tin-sealed casings tested had free bacterial permeability at the seal, and the mechanically tightest seal gave no reproducible resistance against bacterial passage. Industrial cleanliness of cooling water and dry storage were also discussed from standpoint of food sanitation. 


\section{References}

1) Ueno, S.: Gyonilu Soseiji Kyokai Kaiho, 15, 4 (1956).

2) SumizU, W.: ibid, 20, 5 (1957).

3) Ueno, S., Hashimoto T. and ShimizU Y.: this Journal, 24, 559 (1958).

4) Ueno, S.: Text at the Fish Sausage Gijutsu Koshukai, Osaka, March 1960.

5) SAWADA, S.: ibid, Tokyo, October 1960.

6) Hartman, M. W., Power J. J. and Pratt D. E.: Food Teeh., 17, 92 (1963). 